\title{
Proteinase 3 expression on the neutrophils of patients with paroxysmal nocturnal hemoglobinuria
}

\author{
HUI LIU*, YI LIU*, YI LI, ZHAOYUN LIU, LIYAN LI, SHAOXUE DING, YIHAO WANG, \\ TIAN ZHANG, LIJUAN LI, ZONGHONG SHAO and RONG FU
}

Department of Hematology, Tianjin Medical University General Hospital, Tianjin 300052, P.R. China

Received January 11, 2017; Accepted July 20, 2017

DOI: $10.3892 /$ etm.2017.5662

\begin{abstract}
Proteinase 3 (PR3) is released from neutrophils and regulates platelet activity, which is associated with cluster of differentiation (CD)177 antigen (NB1), a glycosylphosphatidylinositol-linked protein. In the present study, the effect of PR3 on thrombosis in paroxysmal nocturnal hemoglobinuria (PNH) and PNH-aplastic anemia (AA) syndrome was explored. The expression of PR3 and NB1 on CD59- neutrophils was detected by flow cytometry, immunofluorescence (IF), reverse transcription-quantitative polymerase chain reaction analysis and western blotting. Serum levels of PR3, proteinase-activated receptor 1 (PAR1) and D-Dimer were measured using ELISAs. The expression of PR3 and NB1 on the plasma membrane of CD59- neutrophils in patients with PNH/PNH-AA was significantly lower compared with their expression on $\mathrm{CD} 59^{+}$neutrophils in patients and controls $(\mathrm{P}=0.001)$. However, no correlation between PR3 and NB1 expression was identified. IF staining further demonstrated partially positive PR3 expression on CD59- neutrophils. The serum level of PR3 in patients was identified to be significantly decreased compared with healthy controls $(\mathrm{P}<0.0001)$, and significantly negatively correlated with PAR1 $(\mathrm{r}=-0.456 ; \mathrm{P}=0.043)$ and $\mathrm{D}$-Dimer $(\mathrm{r}=-0.503 ; \mathrm{P}=0.028)$ levels. The mRNA and protein levels of PR3 on PNH clones did not change significantly compared with the control group. In conclusion, PR3 expression on the plasma membrane of neutrophils and in the serum of patients with PNH/PNH-AA decreased, which may result in increased PAR1 expression and increased clotting. The present study provides the basis for further study on platelets in $\mathrm{PNH}$.
\end{abstract}

Correspondence to: Dr Zonghong Shao or Dr Rong Fu, Department of Hematology, Tianjin Medical University General Hospital, 154 Anshan Street, Tianjin 300052, P.R. China

E-mail: shaozonghong@sina.com

E-mail: florai@sina.com

*Contributed equally

Key words: paroxysmal nocturnal hemoglobinuria, proteinase 3, cluster of differentiation 177 antigen, thrombosis

\section{Introduction}

Paroxysmal nocturnal hemoglobinuria $(\mathrm{PNH})$ is a rare acquired clonal disorder caused by a somatic mutation in the phosphatidylinositol N-acetylglucosaminyltransferase subunit A gene of multipotent hematopoietic stem cells (1). This leads to defects in the biosynthesis of glycosylphosphatidylinositol (GPI) and GPI-linked proteins, including complement decay-accelerating factor and the cluster of differentiation (CD)59, which are particularly sensitive to complement regulation (1-3). As a consequence, the absence of GPI-linked proteins induces intravascular hemolysis, bone marrow failure and life-threatening venous thrombosis (4-6). Thrombosis, which can occur in veins and arteries, is the most frequent complication of PNH and has a high mortality rate. Venous thrombosis can occur in the majority of organs, including the liver, lung, brain, kidney, spleen and bowel (7). A previous study demonstrated that a number of factors contributed to thrombosis in patients with $\mathrm{PNH}$, including free hemoglobin, nitric oxide (NO) depletion, damaged endothelial cells, deregulation of the fibrinolytic system and platelet activation (8). However, the mechanism of thrombosis in patients with PNH is complex and remains unclear.

The glycoprotein CD177 antigen (NB1) is a GPI-linked protein that belongs to the lymphocyte antigen 6 superfamily, which also includes CD59 $(9,10)$. NB1 was first reported in isoimmune neonatal neutropenia (11), but was later identified in transfusion-related acute lung injury, myeloproliferative neoplasms, gastric cancer and Wegener's granulomatosis associated with vasculitis (12-16). NB1 binds to platelet endothelial cell adhesion molecule to promote neutrophil migration and is involved in the inflammatory response $(17,18)$. Proteinase 3 (PR3) is a neutrophil-derived serine proteinase that is primarily stored in azurophil granules in polymorphonuclear leukocytes. PR 3 degrades a variety of matrix proteins, including fibronectin, laminin, vitronectin and collagen type IV (19), and regulates platelet activation through the cleavage and inactivation of proteinase-activated receptor 1 (PAR1), which is expressed on plasma membranes and is associated with NB1 $(20,21)$. The present study aimed to investigate the expression of PR3 and NB1 in neutrophils, and explore the association between PR3 and thrombosis in patients with $\mathrm{PNH}$ or $\mathrm{PNH}$-aplastic anemia (AA) syndrome. 


\section{Patients and methods}

Patients. A total of 21 patients with classical PNH, 6 patients with PNH-AA syndrome and 25 healthy controls were enrolled in the present study. The patients with PNH and PNH-AA syndrome consisted of 14 males and 13 females, with median age of 29 years old (range, 21-43 years). All patients were recruited from the Department of Hematology of Tianjin Medical University General Hospital (Tianjin, China) between November 2014 and February 2016, and diagnosed according to the criteria for PNH set out by the Chinese Medical Association (22). Table I presents the clinicopathological characteristics of the patients included in the present study. There were 7 newly diagnosed patients (6 with PNH and 1 with PNH-AA). All patients exhibited the typical clinical manifestations of PNH and an abnormal expression of CD59 (CD59- granulocytes were $>10 \%$ of total granulocytes), as detected by flow cytometry. Thrombosis was investigated by spiral computed tomography, magnetic resonance imaging or Doppler ultrasound wherever appropriate. A total of 2 patients had cerebral embolisms and 3 patients had portal vein thrombosis, in which 1 patient also had lower limb venous thrombosis.

All patients were treated with corticosteroids (prednisone $0.5 \mathrm{mg} / \mathrm{kg} / \mathrm{day}$, oral administration; Zhejiang Xianju Pharmaceutical Co., Ltd., Zhejiang, China) and vitamin E $(300 \mathrm{mg} / \mathrm{day}$, oral administration; Hebei Tiancheng Pharmaceutical Co., Ltd., Hebei, China) if they exhibited hemolysis. Patients with PNH-AA also received cyclosporine ( $3 \mathrm{mg} / \mathrm{kg} / \mathrm{day}$, oral administration; Huabei Pharmaceutical Co., Ltd., Huabei, China) for $\geq 6$ months. A total of 5 patients with thrombosis were treated with low molecular weight heparin $(0.1 \mathrm{ml} / 10 \mathrm{~kg} / \mathrm{day}$ for 7-14 days, subcutaneous injection; Qilu Pharmaceutical Co., Ltd., Qilu, China) and warfarin (2.5-5 mg/day for 6-12 months, oral administration; Qilu Pharmaceutical Co., Ltd.).

The healthy controls consisted of 15 healthy donors and 10 patients with iron deficiency anemia, 13 males and 12 females, with a median age of 31 years (range, 27-58 years). The present study was approved by the Ethical Committee of Tianjin Medical University (Tianjin, China). Written informed consent was obtained from the patients for the publication of the present study.

Flow cytometry. Fresh peripheral blood $(100 \mu \mathrm{l})$ was collected in EDTA-anticoagulation tubes and incubated with $20 \mu$ lof antibodies directed against CD59 [conjugated with phycoerythrin (PE); 1:5; cat no. 555764; BD Pharmingen; BD Biosciences, San Diego, CA, USA], NB1 (conjugated with allophycocyanin; 1:5; cat no. ab77230) and PR3 [conjugated with fluorescein isothiocyanate (FITC); 1:5; cat no. ab65255; both Abcam, Cambridge, MA, USA]. Their isotype control antibodies (1:5; BD Biosciences) were used as the negative controls. Following incubation in the dark for $30 \mathrm{~min}$ at room temperature, red blood cells were lyzed with $10 \mathrm{ml}$ erythrocytolysin solution (BD Biosciences) and then centrifuged at room temperature at $150 \mathrm{x}$ g for $5 \mathrm{~min}$. The cells were then washed twice with PBS. Finally, the cells were resuspended in $300 \mathrm{ul}$ PBS. Flow cytometry was performed using a BD FACSCalibur ${ }^{\mathrm{TM}}$ Flow Cytometer (BD Biosciences) and $\geq 20,000$ events were acquired for each sample. All results were analyzed using CellQuest $^{\mathrm{TM}}$ Pro Software 4.0.2 (BD Biosciences).

ELISA. The levels of PR3, NB1 and PAR1 in the serum were measured by ELISA. Briefly, $100 \mu$ l of diluted (1:100) capture antibodies directed against PR3 (Human proteinase-antineutrophil cytoplasmic antibody; PR3-ANCA ELISA kit; cat no. fk1344Y; R\&D Systems, Inc, Minneapolis, MN, USA), NB1 (CD177 ELISA kit; cat no. EH1752; Cusabio Biotech Co., Ltd., Wuhan, China) or PAR1 (Human Protease Activated Receptor 1 ELISA kit; cat no. SEC939Hu; Cloud-Clone Corp., Katy, TX, USA) were added to each well and the plates were incubated at $4^{\circ} \mathrm{C}$ overnight. The plates were washed three times, then $200 \mu \mathrm{l}$ assay diluent was added to each well, and the plates were incubated for $1 \mathrm{~h}$ at room temperature. The plates were then washed three times, and diluted standards and the sera $(100 \mu \mathrm{l})$ of the patients and controls were added to the wells in duplicate, after which the plates were incubated for $2 \mathrm{~h}$ at room temperature. Following another wash, $100 \mu \mathrm{l}$ of a diluted $(20 \mathrm{ng} / \mathrm{ml})$ working detector was added to each well and the plates were incubated for $1 \mathrm{~h}$ at room temperature. The wells were washed seven times. Then, 3,3',5,5'-tetramethylbenzidine 1:100 substrate solution was added to each well and the samples were incubated in the dark at room temperature for $30 \mathrm{~min}$. Stop solution was added and the optical density at $450 \mathrm{~nm}$ was measured within 30 min using a VersaMax ${ }^{\mathrm{TM}}$ ELISA Microplate Reader (Molecular Devices, LLC, Sunnyvale, CA, USA).

Neutrophil isolation. Neutrophils were isolated from the peripheral blood of patients with PNH/PNH-AA and healthy controls. Briefly, $5 \mathrm{ml}$ peripheral blood was collected into a tube containing $2 \mathrm{mM}$ EDTA. Then, the blood was layered over a Ficoll Paque Plus solution (cat no. 17-1440-02; GE Healthcare, Chicago, IL, USA) and centrifuged at room temperature for $20 \mathrm{~min}$ at $700 \mathrm{x} \mathrm{g}$ according to the manufacturer's protocol. Neutrophils were isolated from the buffy coat layer and washed with PBS without calcium or magnesium. The cells were then washed twice with PBS and centrifuged at room temperature at $200 \mathrm{x}$ g for $10 \mathrm{~min}$. If the neutrophil solution mixed with red blood cells, Red Blood Cell Lysis Buffer (Sigma-Aldrich; Merck KGaA, Darmstadt, Germany) was used to lyse the red blood cells before the neutrophils were quantified.

PNH clone sorting by magnetic-activated cell sorting (MACS). In $90 \mu \mathrm{l}$ autoMACS Running buffer (Miltenyi Biotec GmbH, Bergisch Gladbach, Germany) 10,000,000 cells were resuspended, according to manufacturer's protocol. Then, $20 \mu \mathrm{l} \mathrm{CD59-PE}$ and $20 \mu \mathrm{l}$ PE MicroBeads (Miltenyi Biotec $\mathrm{GmbH}$ ) were added and the cells were incubated at $4^{\circ} \mathrm{C}$ in the dark for $20 \mathrm{~min}$. Following a wash with $2 \mathrm{ml}$ of the buffer, the cells were centrifuged at room temperature at $300 \mathrm{x} \mathrm{g}$ for $5 \mathrm{~min}$. The cells were then resuspended in $500 \mu \mathrm{l}$ of the buffer. The LD column was placed in the magnetic field of a suitable Quadro MACS separator (both Miltenyi Biotec $\mathrm{GmbH})$. Following the preparation of the column by rinsing it with $2 \mathrm{ml}$ of the buffer, the cells were applied to the column. The flow through containing unlabeled cells was collected. Finally, the column was washed with $2 \mathrm{ml}$ of the buffer. The purity of the PNH clone (CD59- cells) was detected by flow cytometry. 
Table I. Clinicopathological characteristics of the patients included in the present study.

\begin{tabular}{|c|c|c|c|c|c|c|c|c|}
\hline Patient no. & $\begin{array}{c}\text { Age } \\
\text { (years) }\end{array}$ & Gender & Diagnosis & $\begin{array}{c}\text { PNH clone } \\
\text { granulocytes }(\%)\end{array}$ & WBC $\left(\times 10^{9} / 1\right)$ & $\mathrm{Hb}(\mathrm{g} / \mathrm{l})$ & $\operatorname{PLT}\left(\times 10^{9} / 1\right)$ & $\operatorname{RET}(\%)$ \\
\hline 1 & 38 & $\mathrm{~F}$ & PNH-AA & 19.33 & 5.96 & 106 & 113 & 5.15 \\
\hline 2 & 43 & $\mathrm{~F}$ & PNH-AA & 30.23 & 3.56 & 98 & 110 & 6.12 \\
\hline 3 & 21 & $\mathrm{~F}$ & PNH-AA & 20.83 & 3.30 & 87 & 80 & 5.40 \\
\hline $4^{b}$ & 55 & M & PNH-AA & 33.43 & 2.70 & 70 & 254 & 6.01 \\
\hline 5 & 26 & M & $\mathrm{PNH}$ & 50.68 & 4.58 & 133 & 80 & 0.80 \\
\hline 6 & 13 & $\mathrm{~F}$ & $\mathrm{PNH}$ & 88.84 & 3.34 & 91 & 42 & 7.84 \\
\hline 7 & 33 & $\mathrm{~F}$ & $\mathrm{PNH}$ & 63.21 & 7.27 & 81 & 223 & 9.16 \\
\hline $8^{\mathrm{a}, \mathrm{b}}$ & 25 & $\mathrm{~F}$ & $\mathrm{PNH}$ & 85.46 & 4.73 & 76 & 71 & 7.88 \\
\hline 9 & 25 & $\mathrm{~F}$ & $\mathrm{PNH}$ & 78.11 & 2.88 & 83 & 92 & 6.70 \\
\hline $10^{\mathrm{a}, \mathrm{b}}$ & 24 & $\mathrm{~F}$ & $\mathrm{PNH}$ & 97.98 & 1.34 & 67 & 36 & 4.95 \\
\hline $11^{\mathrm{a}}$ & 58 & M & $\mathrm{PNH}$ & 86.75 & 3.62 & 114 & 38 & 3.92 \\
\hline 12 & 50 & $\mathrm{~F}$ & $\mathrm{PNH}$ & 45.54 & 4.20 & 85 & 123 & 5.70 \\
\hline 13 & 46 & $\mathrm{~F}$ & $\mathrm{PNH}$ & 62.32 & 5.50 & 87 & 219 & 4.20 \\
\hline 14 & 24 & $\mathrm{~F}$ & $\mathrm{PNH}$ & 57.88 & 3.90 & 84 & 111 & 3.80 \\
\hline $15^{\mathrm{a}, \mathrm{b}}$ & 20 & M & $\mathrm{PNH}$ & 92.57 & 3.91 & 76 & 51 & 3.37 \\
\hline 16 & 46 & M & PNH-AA & 31.23 & 3.55 & 111 & 75 & 5.35 \\
\hline $17^{\mathrm{a}, \mathrm{b}}$ & 27 & $\mathrm{~F}$ & PNH & 59.41 & 1.40 & 50 & 28 & 4.90 \\
\hline 18 & 11 & M & PNH & 55.60 & 6.10 & 78 & 102 & 5.10 \\
\hline 19 & 27 & M & PNH & 66.38 & 19.34 & 110 & 68 & 4.26 \\
\hline $20^{\mathrm{b}}$ & 29 & M & PNH & 93.60 & 5.90 & 61 & 78 & 8.50 \\
\hline 21 & 15 & M & PNH-AA & 10.98 & 4.80 & 108 & 310 & 1.10 \\
\hline $22^{b}$ & 43 & M & PNH & 56.37 & 10.59 & 63 & 56 & 8.36 \\
\hline 23 & 33 & M & $\mathrm{PNH}$ & 80.64 & 10.32 & 89 & 92 & 7.76 \\
\hline 24 & 16 & $\mathrm{~F}$ & PNH & 92.00 & 7.69 & 98 & 158 & 10.30 \\
\hline 25 & 22 & M & PNH & 50.34 & 7.10 & 79 & 88 & 5.89 \\
\hline 26 & 45 & M & $\mathrm{PNH}$ & 87.11 & 5.60 & 87 & 77 & 5.21 \\
\hline 27 & 32 & M & $\mathrm{PNH}$ & 98.20 & 6.10 & 91 & 67 & 8.90 \\
\hline
\end{tabular}

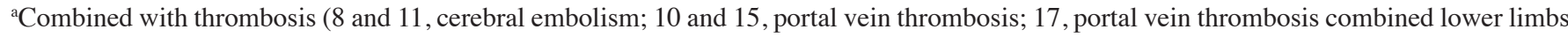
venous thrombosis). ${ }^{b}$ Newly diagnosed patients. PNH, paroxysmal nocturnal hemoglobinuria; AA, aplastic anemia; M, male; F, female; WBC, white blood cells; Hb, hemoglobin; PLT, platelets; RET, reticulocytes.

Immunofluorescence (IF). The sorted PNH cells were collected for smear. The cells were smeared on a coverslip and then the smear was rinsed with PBS three times (5 min each) and blocked with $1 \%$ BSA (Sigma-Aldrich; Merck KGaA) at room temperature for $30 \mathrm{~min}$. Then the coverslips were incubated with anti-PR3 (1:50; cat no. ab65255) and anti-NB1 (1:50; cat no. ab26013; both Abcam) antibodies conjugated with FITC at $4^{\circ} \mathrm{C}$ overnight and washed with PBS three times. Then, the coverslips were stained at room temperature with hematoxylin for $1 \mathrm{~min}$ and rinsed with ammonium hydroxide. Following the coverslips being washed two times with PBS ( 3 min each), the coverslips were blocked for 3 days at room temperature, with glycerin and viewed under an oil immersion lens (magnification, x1000; Olympus Corporation, Tokyo, Japan).

Isolation of total RNA and reverse transcription-quantitative polymerase chain reaction $(R T-q P C R)$ analysis. Total RNA was extracted from the neutrophils using TRIzol ${ }^{\mathrm{TM}}$ reagent (Invitrogen; Thermo Fisher Scientific, Inc., Waltham, MA,
USA). From the purified RNA, $1 \mu \mathrm{g}$ was used for the RT-qPCR analysis using the SuperScript ${ }^{\mathrm{TM}}$ First-Strand Synthesis system for RT-PCR (Invitrogen; Thermo Fisher Scientific, Inc.). The RT-qPCR was performed using SYBR ${ }^{\circledR}$ Premix Ex Taq ${ }^{\mathrm{TM}}$ (Tli RNaseH Plus), ROX plus and the Thermal Cycler Dice Real Time system (both Takara Bio, Inc., Otsu, Japan) in a 96-well plate according to the manufacturer's protocol. The amplification utilized 45 cycles at $95^{\circ} \mathrm{C}$ for $30 \mathrm{sec}$ and $56.7^{\circ} \mathrm{C}$ for $30 \mathrm{sec}$, with the extension at $72^{\circ} \mathrm{C}$ for $30 \mathrm{sec}$. The primers used for the RT-qPCR were as follows: PR3 forward (F), 5'-ACGCGG AGAACAAACTGAAC-3' and reverse (R), 5'-AGGGACGAA AGTGCAAATGT-3'; and NB1 F, 5'-GCAGAGACTTCAGGG TGCTC-3' and R, 5'-CGACACATTTCTAACGACACG-3'. Human $\beta$-actin was used as a housekeeping gene for quantity normalization with the following primer sequences: F, 5'-CTG GAACGGTGAAGGTGACA-3' and R, 5'-AAGGGACTTCCT GTAACAATGCA-3'. The PR3 and NB1 levels were calculated using the $2^{-\Delta \Delta \mathrm{Cq}}$ method (23) following normalization of the data. 
Western blotting. Isolated neutrophils were lysed in RIPA buffer (R\&D Systems, Inc., Minneapolis, MN, USA) supplemented with complete protease inhibitor and phosphatase inhibitors (both Roche Diagnostics, Basel, Switzerland). Protein levels were detected using bicinchoninic acid assay kit (Thermo Fisher Scientific, Inc.). A total $40 \mu \mathrm{g}$ protein/lane were separated by SDS-PAGE on a $12 \%$ gel and transferred to nitrocellulose membranes (EMD Millipore, Billerica, MA, USA). The membranes were blocked with $5 \%$ milk (BD Biosciences) for $1 \mathrm{~h}$ at room temperature, followed by incubation with primary antibodies, anti-PR3 (1:50; cat no. ab65255, Abcam) and GAPDH (1:1,000; Anti-GAPDH Monoclonal Antibody; cat no. A01020; Abbkine Scientific Co., Ltd., Wuhan, China) at $4^{\circ} \mathrm{C}$ overnight. The membranes were washed with Tris-buffered saline with Tween-20 $(20 \mathrm{mM}$ Tris- $\mathrm{HCl}$ buffer, $\mathrm{pH}=7.4$, containing $150 \mathrm{mM} \mathrm{NaCl}$ and $0.05 \%$ Tween-20) three times and then incubated with secondary antibodies horseradish peroxidase-labeled goat anti-mouse Immunoglobulin G (1:2,500; cat no. ab6789; Abcam) at room temperature for $2 \mathrm{~h}$. The reaction was detected with Super ECL Plus Detection Reagent (Thermo Fisher Scientific, Inc.). Protein levels were normalized to GAPDH.

Statistical analysis. Results for each group are expressed as the median (serum level of D-Dimer) or mean \pm standard error of the mean (PR3, NB1 and PAR1 levels). Statistical analysis was performed using one-way analysis of variance followed by a Dunnett's post hoc test. The t-test was performed for two groups. Correlations between different percentages of PR3 and all variables was determined using Spearman's correlation coefficient. Data were analyzed using GraphPad Prism software (version 5.0; GraphPad Software, San Diego, CA, USA). $\mathrm{P}<0.05$ was considered to indicate a statistically significant difference.

\section{Results}

$P R 3$ and NB1 expression on the neutrophil plasma membranes of patients with PNH/PNH-AA is decreased but not correlated. The mRNA levels of PR3 and NB1 were detected in 27 patients with PNH/PNH-AA and 25 healthy controls by flow cytometry (Fig. 1A and B). The expression of $\mathrm{NB1}$ on CD59- neutrophils (CD59- $\left.{ }^{-} \mathrm{NB}^{+} / \mathrm{CD}^{-} 9^{-}\right)$ in patients with $\mathrm{PNH} / \mathrm{PNH}-\mathrm{AA}(20.61 \pm 26.07 \%)$ was significantly lower compared with the $\mathrm{CD} 59^{+}$neutrophils $\left(\mathrm{CD} 59^{+} \mathrm{NB}^{+} / \mathrm{CD}^{2} 9^{+}\right)$in patients with $\mathrm{PNH} / \mathrm{PNH}-\mathrm{AA}$ (72.25 $\pm 25.62 \%, \mathrm{P}=0.001)$ and healthy controls $(67.72 \pm 19.6 \%$, $\mathrm{P}=0.001$ ) (Fig. 1C1). The expression of $\mathrm{PR} 3$ on $\mathrm{CD}^{-} 9^{-}$neutrophils $\left(\mathrm{CD}^{-} 9^{-} \mathrm{PR}^{+} / \mathrm{CD}^{-} 9^{-}\right)$in patients with $\mathrm{PNH} / \mathrm{PNH}-\mathrm{AA}$ $(70.40 \pm 29.86 \%)$ was significantly lower compared with the healthy control group $(93.28 \pm 10.53 \%, \mathrm{P}=0.001)$ and CD59 ${ }^{+}$neutrophils $\left(\mathrm{CD} 59^{+} \mathrm{PR} 3^{+} / \mathrm{CD} 59^{+}\right)$in patients with PNH/PNH-AA $(85.68 \pm 22.21 \%, \mathrm{P}=0.011)$ (Fig. 1C2). The expression of $\mathrm{PR} 3$ in the two latter demonstrated no significant differences $(\mathrm{P}=0.252)$.

Notably, PR3 mRNA expression did not correlate with NB1 mRNA expression ( $r=0.194$; $\mathrm{P}=0.393$; Fig. 1C3), indicating that PR3 expression is not associated with NB1. In order to explore the association between PR3 and NB1, their expression levels on CD59- neutrophils were detected by IF.
The results demonstrated that PR3 was partially expressed in patients with PNH/PNH-AA (Fig. 1D), whereas NB1 was not expressed in patients with PNH/PNH-AA due to a defect in the GPI anchor (Fig. 1E).

$P R 3$ in the serum of patients with PNH/PNH-AA is decreased, which is negatively correlated with PARI and D-Dimer levels. PAR1 and D-Dimer are associated with thrombosis, thus their protein levels were investigated. The serum level of PAR1 in patients with PNH/PNH-AA $(1.38 \pm 0.96 \mu \mathrm{g} / \mathrm{l})$ was significantly higher compared with that in the healthy controls $(0.47 \pm 0.29 \mu \mathrm{g} / \mathrm{l})(\mathrm{P}<0.001$; Fig. $2 \mathrm{~A})$. The serum level of PR3 in patients with PNH/PNH-AA $(2,262.72 \pm 802.80 \mathrm{pg} / \mathrm{ml})$ was significantly lower compared with that in the healthy controls $(3,292.92 \pm 651.68 \mathrm{pg} / \mathrm{ml}) \quad(\mathrm{P}<0.0001$; Fig. 2B $)$. However, the serum level of NB1 in patients with PNH/PNH-AA $(3.881 \pm 0.1663 \mathrm{ng} / \mathrm{ml})$ demonstrated no significant difference compared with that in the healthy controls $(3.840 \pm 0.1188 \mathrm{ng} / \mathrm{ml})$ ( $\mathrm{P}=0.20071$; Fig. 2C).

The median level of D-Dimer in patients with $\mathrm{PNH} / \mathrm{PNH}$ AA (511 ng/dl) was significantly higher compared with the healthy controls $(343 \mathrm{ng} / \mathrm{dl})(\mathrm{P}=0.04$; data not shown). Furthermore, the level of D-Dimer between the patients with thrombosis (Table II) and without thrombosis was compared. The results revealed that the median level of D-Dimer in the 5 patients with thrombosis $(2,104 \mathrm{ng} / \mathrm{dl})$ was significantly increased compared with those without thrombosis $(226 \mathrm{ng} / \mathrm{dl})(\mathrm{P}=0.001$; data not shown). In addition, the levels of D-Dimer ( $\mathrm{r}=-0.503 ; \mathrm{P}=0.028 ;$ Fig. 2D) and PAR1 ( $r=-0.456 ; P=0.043$; Fig. 2E) were significantly negatively correlated with the level of PR3.

PNH clones exhibit no significant difference in $m R N A$ and protein levels of PR3 and NBI compared with neutrophils from the healthy controls. CD59- neutrophils were sorted by MACS following their isolation from the neutrophils of the patients. The purity of CD59- cells, sorted by MACS (Fig. 3A, B), was $>85 \%$. The expression of PR3 and NB1 in CD59 cells in the patients and controls (CD59+ cells) was then analyzed by RT-qPCR and western blot analyses.

The mRNA level of PR3 in patients with PNH/PNH-AA $(1.344 \pm 0.3679)$ demonstrated that there was no significant difference compared with the controls $(1.815 \pm 0.5005)$ $(\mathrm{P}=0.4439$; Fig. 3C). Similarly, the mRNA level of NB1 in the patients with PNH/PNH-AA $(1.826 \pm 0.4010)$ and the healthy controls $(1.485 \pm 0.3563)$ demonstrated no significant difference ( $\mathrm{P}=0.5359$; Fig. 3D). The western blotting results revealed that there was no marked difference in PR3 protein levels between patients with PNH/PNH-AA and the healthy control group (Fig. 3E).

\section{Discussion}

Thromboembolism is the primary cause of mortality in patients with PNH and usually occurs in the hepatic veins, which leads to Budd-Chiari syndrome, the cerebral veins and sinuses. Thus far, the mechanism of thrombosis in PNH has been unclear. NO synthesis in endothelial cells maintains normal flow of blood and inhibits platelet aggregation. In patients with PNH, extensive intravascular hemolysis results in the production of large amounts of free hemoglobin in plasma. The free hemoglobin 
Table II. PR3, NB1 and D-Dimer serum levels in patients with paroxysmal nocturnal hemoglobinuria combined with thrombosis.

\begin{tabular}{|c|c|c|c|c|c|c|}
\hline Patient no. & $\mathrm{G}, \mathrm{CD}^{-} 9^{-}(\%)$ & $\begin{array}{c}\text { D-Dimer } \\
\text { level (ng/dl) }\end{array}$ & $\begin{array}{c}\text { CD59-PR3+/ } \\
\text { CD59- }(\%)\end{array}$ & $\begin{array}{l}\mathrm{CD}^{\mathrm{C} 9} 9^{+} \mathrm{PR}^{+} / \\
\mathrm{CD} 59^{+}(\%)\end{array}$ & $\begin{array}{l}\text { CD59-NB1+/ } \\
\text { CD59- }(\%)\end{array}$ & $\begin{array}{c}\mathrm{CD}^{\mathrm{C}^{+} \mathrm{NB}^{+}}{ }^{+}(\%)\end{array}$ \\
\hline 8 & 85.46 & 830 & 24 & 25 & 11 & 81 \\
\hline 10 & 97.98 & 2,104 & 56 & 91 & 16 & 80 \\
\hline 11 & 86.75 & 1,355 & 79 & 86 & 1 & 13 \\
\hline 15 & 92.57 & 5,324 & 99 & 99 & 0.9 & 93 \\
\hline 17 & 59.41 & 5,835 & 96 & 98 & 0.5 & 69 \\
\hline
\end{tabular}

G, granulocytes; CD, cluster of differentiation; PR3, proteinase 3; NB1, CD177 antigen.
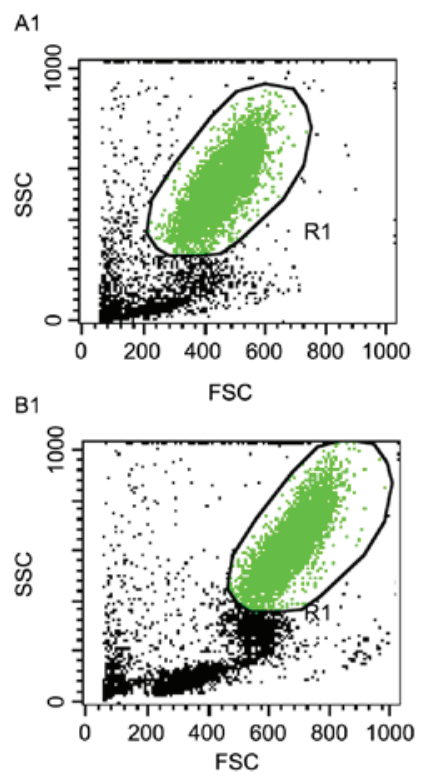

C1

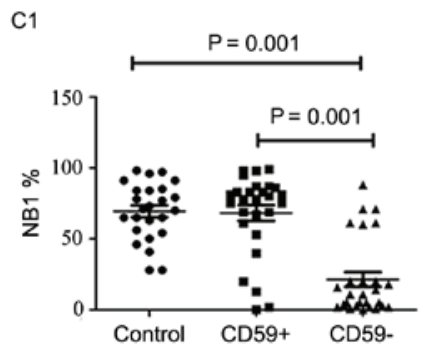

D1

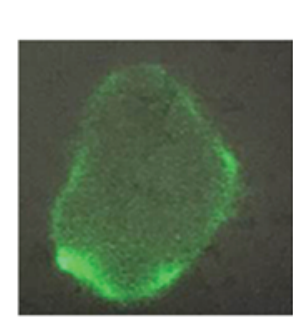

A2

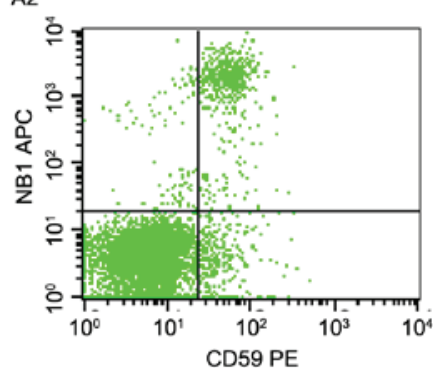

B2

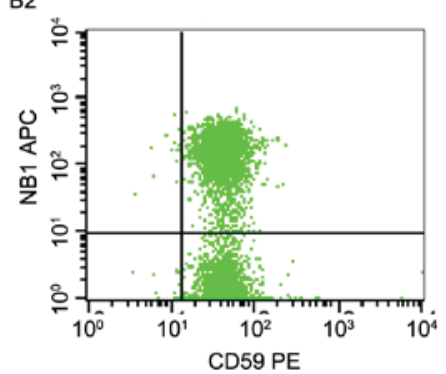

C2

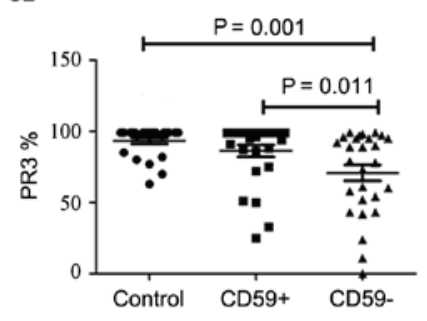

A3

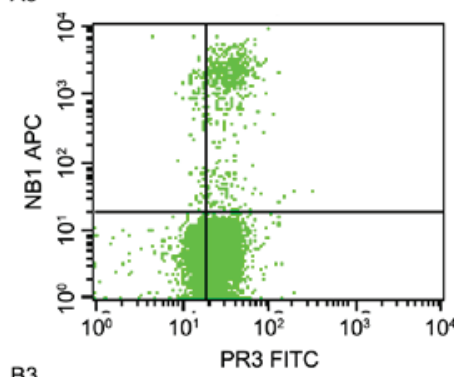

B3

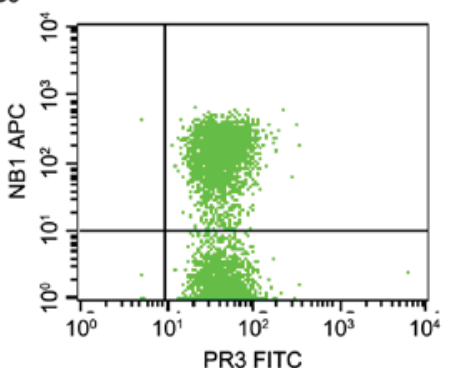

C3

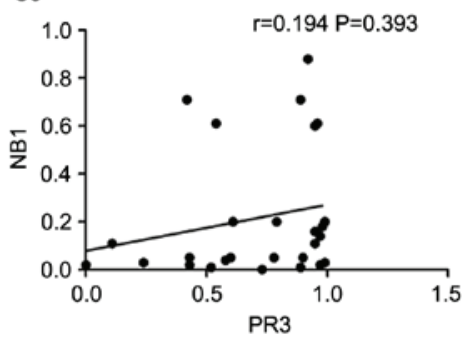

D2

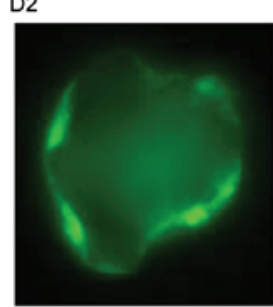

E1

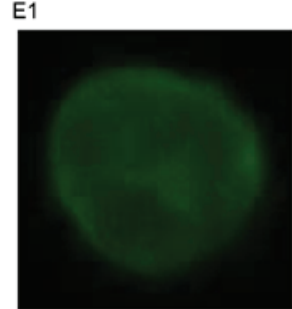

E2

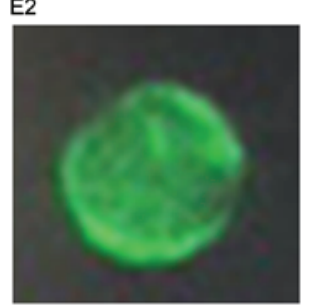

Figure 1. PR3 and NB1 expression on the neutrophil plasma membranes of patients with PNH or PNH-AA is decreased. The expression of PR3 and NB1 were detected by flow cytometry in (A) PNH/PNH-AA patients and (B) healthy controls (presented as the mean \pm standard error of the mean). (A1 and B1) The neutrophils were gated as R1 and then (A2 and B2) NB1 expression was investigated on CD59-/CD59+ neutrophils. (A3 and B3) PR3 and NB1 were demonstrated to be expressed on CD59-/CD59+ neutrophils. (C) Quantification and analysis of the flow cytometry results. (C1 and C2) The results demonstrated that the expression of NB1 and PR3 on CD59- neutrophils significantly decreased compared with $\mathrm{CD}^{-} 9^{+}$neutrophils in patients with $\mathrm{PNH} / \mathrm{PNH}-\mathrm{AA}$ and the healthy controls. (C3) No correlation was identified between PR3 and NB1 expression in patients with PNH/PNH-AA. Furthermore, the expression of these two proteins were measured by immunofluorescence. PR3 was partially expressed on CD59- neutrophils of (D1) patients with PNH/PNH-AA compared with (D2) healthy controls, while no NB1 expression was identified on CD59- neutrophils of (E1) patients with PNH/PNH-AA compared with (E2) healthy controls. SSC, side-scattered light; FSC, forward-scattered light; CD, cluster of differentiation; NB1, CD177 antigen; APC, allophycocyanin; PE, phycoerythrin; PR3, proteinase 3; FITC, fluorescein isothiocyanate; PNH, paroxysmal nocturnal hemoglobinuria; AA, aplastic anemia. 


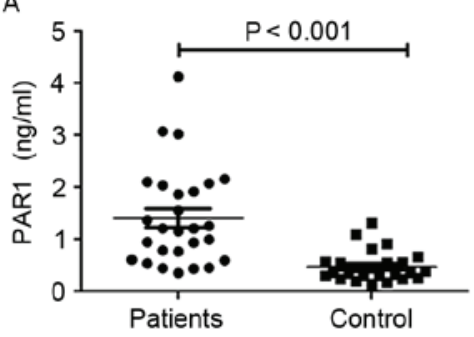

B

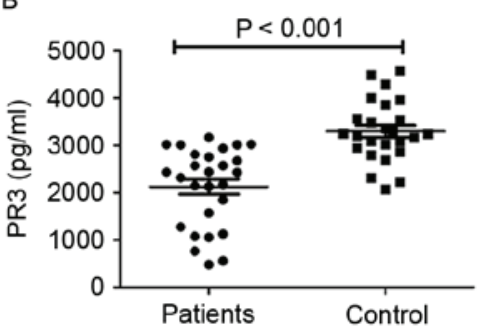

C

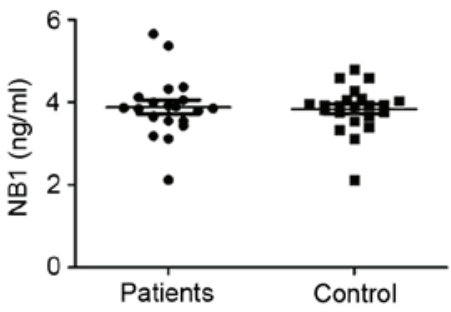

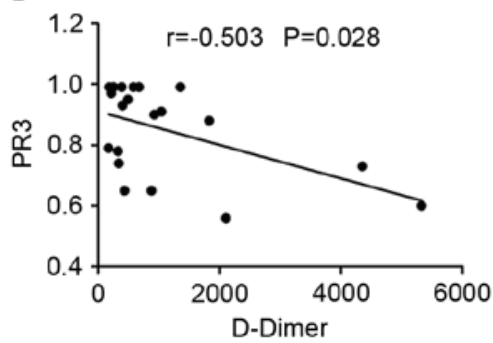

$\mathrm{E}$

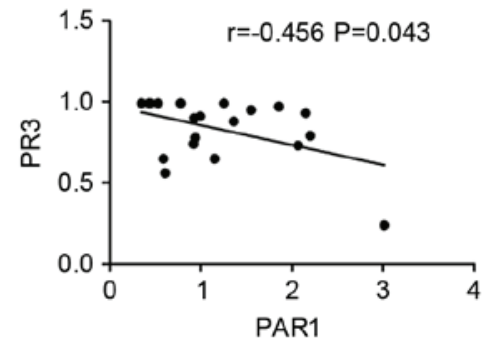

Figure 2. PR3 in the serum of patients with PNH/PNH-AA is decreased, and negatively correlated with PAR1 and D-Dimer levels. In patients with (A) PNH the level of PAR1 increased, while (B) PR3 decreased (presented as the mean \pm standard error of the mean). (C) No significant change in NB1 expression was identified in patients with PNH/PNH-AA compared with healthy controls. The level of PR3 negatively correlated with (D) D-Dimer (presented as the median) and (E) PAR1 levels in patients with PNH/PNH-AA. PAR1, proteinase-activated receptor 1; PR3, proteinase 3; NB1, cluster of differentiation 177 antigen; $\mathrm{PNH}$, paroxysmal nocturnal hemoglobinuria; AA, aplastic anemia.

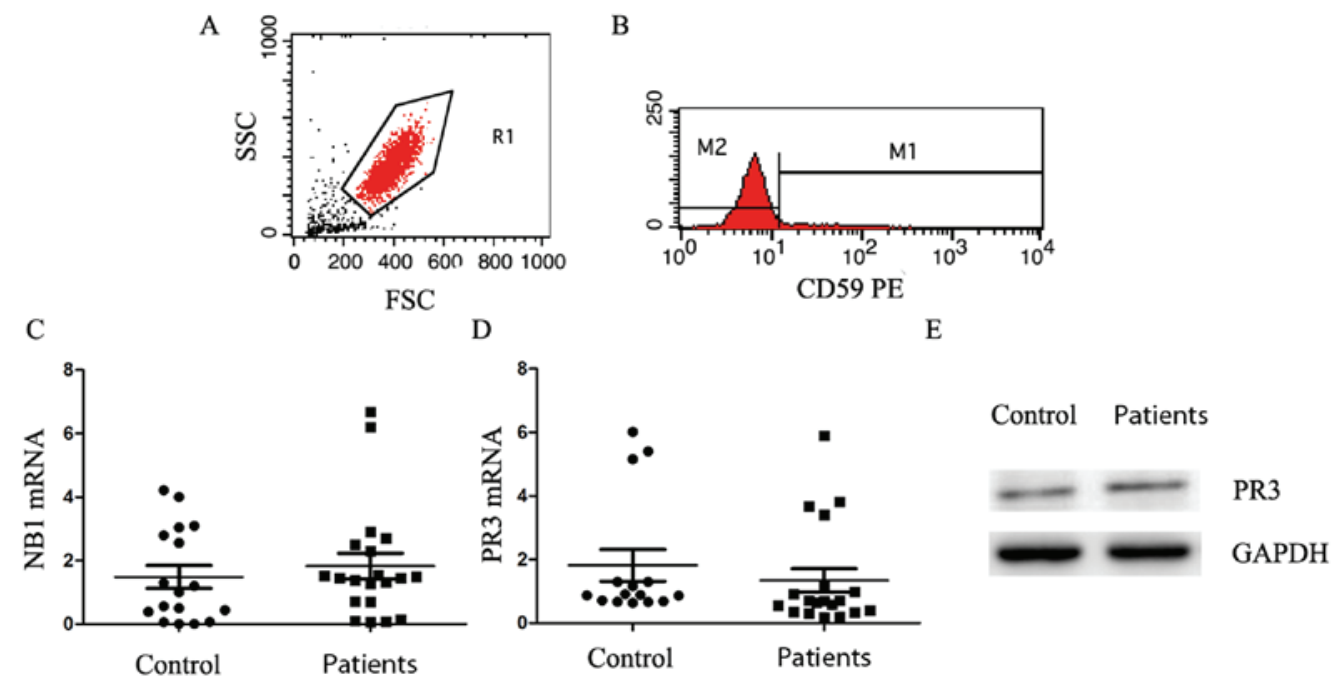

Figure 3. PNH clones exhibit no significant difference in mRNA and protein levels of PR3 and NB1 compared with neutrophils from the controls. (A) The neutrophils were isolated from the blood of patients with PNH/PNH-AA; the purity, detected by flow cytometry, was $>85 \%$. (B) CD59- neutrophils were sorted by magnetic-activated cell sorting and the purity was determined to be $>90 \%$. No significant differences in the mRNA expression of (C) PR3 or (D) NB1 were identified between patients with PNH/PNH-AA and the healthy controls (presented as the mean \pm standard error of the mean). (E) No notable differences in PR3 protein expression were identified between patients with PNH/PNH-AA and the healthy controls. SSC, side-scattered light; FSC, forward-scattered light; $\mathrm{CD}$, cluster of differentiation; NB1, CD177 antigen; PE, phycoerythrin; PR3, proteinase 3; PNH, paroxysmal nocturnal hemoglobinuria; AA, aplastic anemia.

serves a role as a $\mathrm{NO}$ effective scavenger in combination with $\mathrm{NO}$, and $\mathrm{NO}$ is depleted, resulting in platelet aggregation and activation (24,25). Another factor associated with thrombosis is urokinase-type plasminogen activator receptor (uPAR), a GPI-linked protein expressed on neutrophils that mediates endogenous thrombolysis through a urokinase-dependent mechanism (26-28). Sloand et al (29) demonstrated that in patients with PNH, membrane GPI-anchored UPAR is decreased or absent on granulocytes and platelets, while soluble UPAR (suPAR) levels are increased in patients' plasma. Increased levels of su-PAR compete with urokinase receptors on the cell membrane, reducing plasmin production, thereby reducing fibrinolytic activity and promoting thrombosis and stabilization. A previous study demonstrated that the adhesion and aggregation of platelets was compensatively decreased in patients with $\mathrm{PNH}$, particularly in CD59+ platelets (30).

The present study aimed to explore the expression of PR3 and its effect on thrombosis in patients with PNH. Several studies have suggested that there is an association between NB1 and PR3, which are co-expressed on the plasma membrane of the same subset of neutrophils; these studies indicated that NB1 is a receptor of PR3 $(16,31-33)$. However, Hu et al $(34,35)$ 
demonstrated that neutrophils from NB1 negative individuals expressed low levels of PR3 following priming with tumor necrosis factor aumor necrosis factor low leis not an exclusive binding partner of PR3. The flow cytometry results in the present study demonstrated that PR3 and NB1 expression decreased on CD59- neutrophils due to a lack of GPI-linked proteins; however, there was no correlation between PR3 and NB1 expression. In addition, the IF results demonstrated that PR3 was partially expressed on the CD59- neutrophils of patients with PNH, while there was no NB1 expression. A hypothesis for the low expression of PR3 on CD59- neutrophils from patients with $\mathrm{PNH}$ compared with $\mathrm{CD} 59^{+}$neutrophils from patients with PNH and normal controls may be that PR3 binds to other receptor(s) to exert its function.

Furthermore, the level of PR3 in serum was identified to be significantly decreased in patients with PNH/PNH-AA, and negatively correlated with PAR1 and D-Dimer levels. PR3 can degrade PAR1, causing inhibition of active thrombin and regulating platelet activation (21). PAR1 combines with thrombin to induce thrombosis. Thrombin binding to PAR1 on platelets induces platelet activation and strengthens platelet adhesion in order to promote the aggregation of platelets and thus cause thrombosis $(36,37)$. Another study demonstrated that PR3 induced platelets to change shape via the Rho/Rho kinase and $\mathrm{Ca}^{2+}$ signaling pathways (38). The results of the present study indicated that lower PR3 level in serum of patients with $\mathrm{PNH} / \mathrm{PNH}-\mathrm{AA}$ resulted in increased PAR1 level, and thus an increased concentration of activated platelets. To investigate the hypothesis of NB1 regulation of PR3 expression, RT-qPCR analysis was performed. No significant difference in PR3 and NB1 mRNA levels was identified between the patients with $\mathrm{PNH} / \mathrm{PNH}-\mathrm{AA}$ and the control group. Thus, this hypothesis was not validated.

In conclusion, the expression of PR3 on the plasma membrane of neutrophils decreased in patients with PNH/PNH-AA, but was still partially expressed. The level of PR3 in the serum of patients with PNH/PNH-AA also decreased, which lead to an increase in PAR1 expression, indicating increased platelet activation. However, the mechanism regulating $\mathrm{PR} 3$ expression in patients with $\mathrm{PNH}$ requires further exploration in the future.

\section{Acknowledgements}

The present study was supported by the National Natural Science Foundation of China (grant nos. 81570106, 81600088, 81600093 and 81770110), the Tianjin Municipal Natural Science Foundation (grant nos. 14JCYBJC25400 and 15JCYBJC24300), and the Science and Technology Foundation of Tianjin Municipal Health Bureau (grant nos. 2011kz115 and 2014kz120).

\section{References}

1. Hillmen P, Lewis SM, Bessler M, Luzzatto L and Dacie JV: Natural history of paroxysmal nocturnal hemoglobinuria. N Engl J Med 333: 1253-1258, 1995.

2. Takeda J, Miyata T, Kawagoe K, Iida Y, Endo Y, Fujita T, Takahashi M, Kitani T and Kinoshita T: Deficiency of the GPI anchor caused by a somatic mutation of the PIG-A gene in paroxysmal nocturnal hemoglobinuria. Cell 73: 703-711, 1993.
3. Nicholson-Weller A, Spicer DB and Austen KF: Deficiency of the complement regulatory protein, 'decay-accelerating factor,' on membranes of granulocytes, monocytes, and platelets in paroxysmal nocturnal hemoglobinuria. N Engl J Med 312: 1091-1097, 1985.

4. Diep DB, Nelson KL, Raja SM, Pleshak EN and Buckley JT: Glycosylphosphatidylinositol anchors of membrane glycoproteins are binding determinants for the channel-forming toxin aerolysin. J Biol Chem 273: 2355-2360, 1998.

5. Brodsky RA, Mukhina GL, Nelson KL, Lawrence TS, Jones RJ and Buckley JT: Resistance of paroxysmal nocturnal hemoglobinuria cells to the glycosylphosphatidylinositol-binding toxin aerolysin. Blood 93: 1749-1756, 1999.

6. Devalet B, Mullier F, Chatelain B, Dogne JM and Chatelain C: The central role of extracellular vesicles in the mechanisms of thrombosis in paroxysmal nocturnal haemoglobinuria: A review. J Extracell Vesicles 3: 23304, 2014.

7. Ziakas PD, Poulou LS and Pomoni A: Thrombosis in paroxysmal nocturnal hemoglobinuria at a glance: A clinical review. Curr Vasc Pharmacol 6: 347-353, 2008.

8. Hill A, Kelly RJ and Hillmen P: Thrombosis in paroxysmal nocturnal hemoglobinuria. Blood 121: 4985-4996; quiz 5105, 2013.

9. Stroncek DF, Caruccio L and Bettinotti M: CD177: A member of the LY-6 gene superfamily involved with neutrophil proliferation and polycythemia vera. J Transl Med 2: 8, 2004.

10. Kissel K, Santoso S, Hofmann C, Stroncek D and Bux J: Molecular basis of the neutrophil glycoprotein NB1 (CD177) involved in the pathogenesis of immune neutropenias and transfusion reactions. Eur J Immunol 31: 1301-1309, 2001.

11. Lalezari P, Murphy GB and Allen FH Jr: NB1, a new neutrophil-specific antigen involved in the pathogenesis of neonatal neutropenia. J Clin Invest 50: 1108-1115, 1971.

12. Toyoda T, Tsukamoto T, Yamamoto M, Ban H, Saito N, Takasu S, Shi L, Saito A, Ito S, Yamamura Y, et al: Gene expression analysis of a Helicobacter pylori-infected and high-salt diet-treated mouse gastric tumor model: Identification of CD177 as a novel prognostic factor in patients with gastric cancer. BMC Gastroenterol 13: 122, 2013.

13. Teofili L, Martini M, Guidi F, Venditti D, Leone G and Larocca ML: The PRV-1 gene expression in essential thrombocythemia. Blood 104: 2995-2996, 2004.

14. Teofili L, Martini M, Luongo M, Di Mario A, Leone G, De Stefano V and Larocca LM: Overexpression of the polycythemia rubra vera-1 gene in essential thrombocythemia. J Clin Oncol 20: 4249-4254, 2002.

15. Bux J, Becker F, Seeger W, Kilpatrick D, Chapman J and Waters A: Transfusion-related acute lung injury due to HLA-A2-specific antibodies in recipient and NB1-specific antibodies in donor blood. Br J Haematol 93: 707-713, 1996.

16. von Vietinghoff S, Tunnemann G, Eulenberg C, Wellner M, Cristina Cardoso M, Luft FC and Kettritz R: NB1 mediates surface expression of the ANCA antigen proteinase 3 on human neutrophils. Blood 109: 4487-4493, 2007.

17. Saragih H, Zilian E, Jaimes Y, Paine A, Figueiredo C, Eiz-Vesper B, Blasczyk R, Larmann J, Theilmeier G, Burg-Roderfeld M, et al: PECAM-1-dependent heme oxygenase-1 regulation via an Nrf2-mediated pathway in endothelial cells. Thromb Haemost 111: 1077-1088, 2014.

18. Sachs UJ, Andrei-Selmer CL, Maniar A, Weiss T, Paddock C, Orlova VV, Choi EY, Newman PJ, Preissner KT, Chavakis T and Santoso S: The neutrophil-specific antigen CD177 is a counter-receptor for platelet endothelial cell adhesion molecule-1 (CD31). J Biol Chem 282: 23603-23612, 2007.

19. Rao NV, Wehner NG, Marshall BC, Gray WR, Gray BH and Hoidal JR: Characterization of proteinase-3 (PR-3), a neutrophil serine proteinase. Structural and functional properties. J Biol Chem 266: 9540-9548, 1991.

20. Renesto P, Si-Tahar M, Moniatte M, Balloy V, Van Dorsselaer A, Pidard D and Chignard M: Specific inhibition of thrombin-induced cell activation by the neutrophil proteinases elastase, cathepsin G, and proteinase 3: Evidence for distinct cleavage sites within the aminoterminal domain of the thrombin receptor. Blood 89: 1944-1953, 1997.

21. Mihara K, Ramachandran R, Renaux B, Saifeddine M and Hollenberg MD: Neutrophil elastase and proteinase-3 trigger G protein-biased signaling through proteinase-activated receptor-1 (PAR1). J Biol Chem 288: 32979-32990, 2013.

22. Chinese Society of Hematology, Chinese Medical Association: Expert consensus of diagnosis and treatment of paroxysmal nocturnal hemoglobinuria. Zhonghua Xue Ye Xue Za Zhi 34: 276-279, 2013 (In Chinese). 
23. Livak KJ and Schmittgen TD: Analysis of relative gene expression data using real-time quantitative PCR and the 2(-Delta Delta C(T)) method. Methods 25: 402-408, 2001.

24. Qin X, Hu W, Song W, Blair P, Wu G, Hu X, Song Y, Bauer S, Feelisch M, Leopold JA, et al: Balancing role of nitric oxide in complement-mediated activation of platelets from $\mathrm{mCd} 59 \mathrm{a}$ and mCd59b double-knockout mice. Am J Hematol 84: 221-227, 2009.

25. Pu JJ and Brodsky RA: Paroxysmal nocturnal hemoglobinuria from bench to bedside. Clin Transl Sci 4: 219-224, 2014.

26. Rønne E, Pappot H, Grøndahl-Hansen J, Høyer-Hansen G, Plesner T, Hansen NE and Danø K: The receptor for urokinase plasminogen activator is present in plasma from healthy donors and elevated in patients with paroxysmal nocturnal haemoglobinuria. Br J Haematol 89: 576-581, 1995.

27. Ploug M, Plesner T, Rønne E, Ellis V, Høyer-Hansen G, Hansen NE and Danø K: The receptor for urokinase-type plasminogen activator is deficient on peripheral blood leukocytes in patients with paroxysmal nocturnal hemoglobinuria. Blood 79: $1447-1455,1992$

28. Engström G, Zöller B, Svensson PJ, Melander O and Persson M: Soluble urokinase plasminogen activator receptor and incidence of venous thromboembolism. Thromb Haemost 115: 657-662, 2016.

29. Sloand EM, Pfannes L, Scheinberg P, More K, Wu CO, Horne M and Young NS: Increased soluble urokinase plasminogen activator receptor (suPAR) is associated with thrombosis and inhibition of plasmin generation in paroxysmal nocturnal hemoglobinuria (PNH) patients. Exp Hematol 36: 1616-1624, 2008.

30. Fu R, Meng Y, Wang Y, Liu H, Liu Y, Li L, Ding S, Wang G, Song $\mathrm{J}$ and Shao Z: The dysfunction of platelets in paroxysmal nocturnal hemoglobinuria. Thromb Res 148: 50-55, 2016.

31. von Vietinghoff S, Eulenberg C, Wellner M, Luft FC and Kettritz R: Neutrophil surface presentation of the anti-neutrophil cytoplasmic antibody-antigen proteinase 3 depends on N-terminal processing. Clin Exp Immunol 152: 508-516, 2008.
32. Bauer S, Abdgawad M, Gunnarsson L, Segelmark M, Tapper H and Hellmark T: Proteinase 3 and CD177 are expressed on the plasma membrane of the same subset of neutrophils. J Leukoc Biol 81: 458-464, 2007

33. Jankowska AM, Szpurka H, Calabro M, Mohan S, Schade AE, Clemente M, Silverstein RL and Maciejewski JP: Loss of expression of neutrophil proteinase-3: A factor contributing to thrombotic risk in paroxysmal nocturnal hemoglobinuria. Haematologica 96: 954-962, 2011.

34. Hu N, Westra J, Huitema MG, Bijl M, Brouwer E, Stegeman CA, Heeringa P, Limburg PC and Kallenberg CG: Coexpression of CD177 and membrane proteinase 3 on neutrophils in antineutrophil cytoplasmic autoantibody-associated systemic vasculitis: Anti-proteinase 3-mediated neutrophil activation is independent of the role of CD177-expressing neutrophils. Arthritis Rheum 60: 1548-1557, 2009.

35. Hu N, Westra J and Kallenberg CG: Membrane-bound proteinase 3 and its receptors: Relevance for the pathogenesis of Wegener's Granulomatosis. Autoimmun Rev 8: 510-514, 2009.

36. Han Y, Pasquet JM, Nurden A and Ruan CG: Mechanism of action of protease-activated receptors 1 and 4 in platelet activation. Zhongguo Shi Yan Xue Ye Xue Za Zhi 11: 495-498, 2003 (In Chinese).

37. Kahn ML, Nakanishi-Matsui M, Shapiro MJ, Ishihara $\mathrm{H}$ and Coughlin SR: Protease-activated receptors 1 and 4 mediate activation of human platelets by thrombin. J Clin Invest 103: 879-887, 1999.

38. Peng X, Ramström S, Kurz T, Grenegård M and Segelmark M: The neutrophil serine protease PR3 induces shape change of platelets via the $\mathrm{Rho} / \mathrm{Rho}$ kinase and $\mathrm{Ca}(2+)$ signaling pathways. Thromb Res 134: 418-425, 2014. 